\title{
Bone Morphogenetic Protein in Scaphoid Nonunion: A Systematic Review
}

\author{
Michael M. Polmear, MD ${ }^{1}$ Ashley B. Anderson, MD ${ }^{2} \quad$ Paul J. Lanier, DO ${ }^{1} \quad$ Justin D. Orr, MD ${ }^{1}$ \\ Leon J. Nesti, MD, PhD ${ }^{3}$ John C. Dunn, MD ${ }^{1}$ \\ ${ }^{1}$ Department of Orthopaedic Surgery, William Beaumont Army \\ Medical Center, El Paso, Texas \\ ${ }^{2}$ Department of Orthopaedic Surgery, Walter Reed National Military \\ Medical Center, Bethesda, Maryland \\ Address for correspondence Michael M. Polmear, MD, William \\ Beaumont Army Medical Center, Department of Orthopaedic Surgery, \\ 5005 N Piedras St, El Paso, TX 79920 \\ (e-mail: michael.polmear@gmail.com).
}

${ }^{3}$ Department of Surgery, Uniformed Services University of the Health

Sciences, Bethesda, Maryland

J Wrist Surg 2021;10:184-189.

\begin{abstract}
Keywords

- scaphoid

- scaphoid fracture

- bone morphogenetic protein

- scaphoid fixation

- scaphoid nonunion

Background Scaphoid nonunion can lead to carpal collapse and osteoarthritis, a painfully debilitating problem. Bone morphogenetic protein (BMP) has been successfully implemented to augment bone healing in other circumstances, but its use in scaphoid nonunion has yielded conflicting results.

Case Description The purpose of this study is to assess the outcomes and complications of scaphoid nonunion treated surgically with BMP.

Literature Review A literature review of all available journal articles citing the use of BMP in scaphoid nonunion surgery from 2002 to 2019 was conducted. We included studies that used BMP as an adjunct to surgical treatment for scaphoid nonunions in both the primary and revision settings with computed tomography determination of union. Demographic information, dose of BMP, tobacco use, outcomes, and complications were recorded. A total of 21 cases were included from four different studies meeting inclusion criteria.

Clinical Relevance The union rates were $90.5 \%$ overall, $100 \%$ for primary surgeries, and $77.8 \%$ for revision surgeries. Five patients (24\%) experienced 11 complications, including four cases (19\%) of heterotrophic ossification. Use of BMP in scaphoid nonunion surgery resulted in a $90.5 \%$ overall union rate but was also associated with complications such as heterotopic ossification. All included studies used BMP to augment bone graft, screw or wire fixation, or a combination of methods. The efficacy of BMP in scaphoid nonunion is unclear, and a sufficiently powered, randomized controlled trial is needed to determine optimal fixation methods, dosing, and morbidity of the use of BMP.

Level of Evidence This is a Level IC, therapeutic interventional study.
\end{abstract}

The scaphoid is the most commonly fractured carpal bone. ${ }^{1}$ Scaphoid nonunion rates have remained at approximately $10 \%$ over the last two decades with certain factors predisposing to higher nonunion rates, including proximal pole fractures, displaced fractures, unstable fractures with deformity, and

received

April 30, 2020

accepted after revision

November 19, 2020

published online

January 23, 2021

increased time to treatment. ${ }^{2-4}$ Persistent scaphoid nonunion can progress to carpal bone collapse and radiocarpal arthritis.

There are many forms of scaphoid nonunion surgery, including screw fixation, with ${ }^{5}$ and without ${ }^{6}$ vascular pedicle, and free vascularized bone transfer. ${ }^{7,8}$ The gold standard for

(c) 2021. Thieme. All rights reserved.

Thieme Medical Publishers, Inc., 333 Seventh Avenue, 18th Floor, New York, NY 10001, USA
DOI https://doi.org/ $10.1055 / \mathrm{s}-0040-1722332$. ISSN 2163-3916. 
treatment of scaphoid waist nonunion is open reduction and internal fixation with bone graft. ${ }^{3,6,9}$ Autologous bone grafting from the iliac crest (ICBG) and distal radius have comparable healing rates with both osteoconductive and osteoinductive properties but are associated with donor site morbidity, including chronic pain, hematoma formation, fracture, and infection. ${ }^{10-12}$ Donor site morbidity and technical difficulty for free vascularized flaps are also concerns with medial femoral condyle (MFC) $)^{8}$ and medial femoral trochlea (MFT) ${ }^{7}$ grafting. A recent case series ${ }^{13}$ and systematic review ${ }^{14}$ have demonstrated improved efficacy from earlier studies ${ }^{5}$; however, the importance of vascularity remains uncertain in scaphoid nonunion surgery. ${ }^{6}$

It is possible that bone morphogenetic protein (BMP) may facilitate healing in these difficult fractures. BMPs, members of the TGF- $\beta$ family, were first discovered in 1965, and over 20 different types have been identified and implicated in bone formation and fracture healing. ${ }^{15,16}$

The BMPs used most often in orthopedic surgeries are BMP 2, 4, 6, 7, and 9. ${ }^{16}$ No BMP is currently approved by the Food and Drug Administration (FDA) in hand surgery, and rhBMP-2 (recombinant human) is the only BMP that is FDA approved for lumbar interbody fusions and augmenting tibial fracture intramedullary nailing. ${ }^{17-19}$ However, BMP use has increased steadily since its FDA approval in 2002, with over 340,000 BMP uses from 2002 to 2007 , of which $85 \%$ were off-label uses for other orthopedic fractures. ${ }^{17}$ Despite its use in the surgical setting, BMP augmentation for scaphoid nonunion surgery has not been well studied. The use of BMP in scaphoid nonunion surgery has been reported in small case series in either primary or revision settings with variable union and complication rates..$^{20-25}$ The purpose of this systematic review is to analyze the outcomes and complications of BMP use in scaphoid nonunion surgery.

\section{Materials and Methods}

Following the preferred reporting items for systematic reviews and meta-analyses (PRISMA) guidelines, we performed a literature review of scaphoid nonunion surgery with the use of BMP, analyzing union and complication rates. ${ }^{26}$

A systematic search of the English literature was performed for all articles published on the treatment of scaphoid nonunions with BMP using the PubMed, Medline, EMBASE, and Cochrane databases between the years 2002 and 2019. Search terms included, BMP, scaphoid non-unions, osteogenic protein, distal radius bone graft (DRBG), and iliac crest bone graft (ICBG).

The inclusion criteria were papers that reviewed the outcomes and complications of patients with scaphoid nonunion treated with BMP, with or without autograft or allograft, and followed patients until evidence of union by computed tomography (CT). Studies were excluded if fixation was augmented with other materials other than autograft or allograft bone and BMP.

The primary outcome measure was union rate. The secondary outcome measure was complication rate. Complications included persistent nonunion, heterotopic ossification (HO), reoperation, chronic pain, decreased wrist range of motion ( $<40 / 40$ degrees flexion/extension), and infection. Persistent nonunion was described as absence of union at 12 months following surgery with BMP. HO was described as periarticular ossification beyond the scaphoid nonunion following fixation augmented with BMP. Indication for use of BMP in primary and revision settings and amount of BMP used were independent variables. Primary surgeries were defined as procedures performed on scaphoid nonunions following a period of failed nonoperative treatment. Revision surgeries were defined as procedures performed on scaphoid nonunions that had previously undergone surgical fixation.

\section{Data Analysis}

Demographic data, primary outcome measures, and secondary outcome measures from comparable studies were pooled for all patients receiving BMP in the treatment of scaphoid nonunions. Demographic variables of patient age, tobacco use, primary versus revision setting, scaphoid fracture location, initial delay from injury to surgery, amount and type of BMP used, fixation technique, duration of postoperative immobilization, and clinical follow-up were recorded. Heterogeneity in demographic and surgical variables among the included studies were assessed using Cochran's $Q$ and $\mathrm{I}^{2}$ statistics. ${ }^{27,28}$ Complications and reoperations were similarly recorded.

\section{Results}

The literature search resulted in six potentially eligible studies, while four met inclusion and exclusion criteria. One paper by Kujala et al was excluded because it used sea coral as an osteoconductive scaffold bridge for BMP. ${ }^{20}$ One article by Rice and Lubahn described BMP use in nonunions in the hand and wrist, including seven patients with scaphoid nonunion, resulting in radiographic union in five patients and nonunion in two tobacco users seven months postoperatively without any other complications reported; however, all of these cases were excluded for lack of CT determination of union. ${ }^{25}$ One case from Ablove et al that resulted in radiographic union without any reported complications was excluded from their series of four patients for lack of CT determination of union. ${ }^{23}$ Two papers were level IV retrospective studies, ${ }^{23,24}$ one was a level $\mathrm{V}$ case report, ${ }^{21}$ and the remaining one was a level I randomized controlled trial. ${ }^{22}$ (-Table 1) All patients had radiographic or CT evidence of nonunion with median delay from injury to surgery and BMP of 14.5 (range 9-55) months reported for $86 \%(18 / 21)$ of patients. None of the studies received external funding.

Cochran's $Q$ and $I^{2}$ statistics demonstrated considerable heterogeneity among the demographic and surgical variables of patient age, tobacco use, primary versus revision setting, scaphoid fracture location, initial delay from injury to surgery, amount and type of BMP used, fixation technique, duration of postoperative immobilization, and clinical follow-up ( $\left.\mathrm{I}^{2}>95 \%\right)$. Publication bias was not directly assessed by funnel plots and Egger tests as control groups were not reported in $75 \%(3 / 4)$ of included studies. However, the $\mathrm{I}^{2}$ statistic for study size, fracture location, age, tobacco use, 


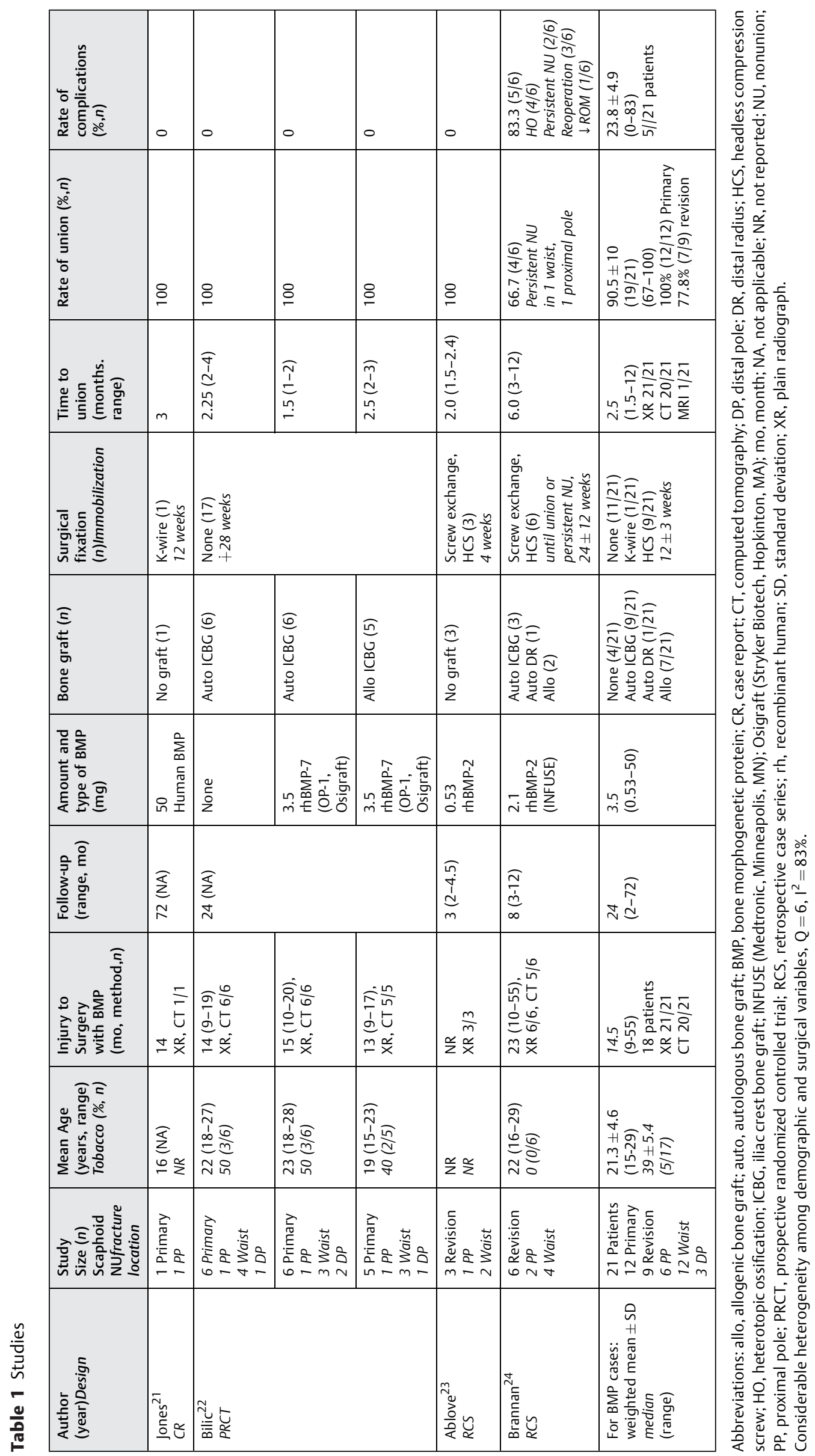


Table 2 Outcome by indication

\begin{tabular}{|l|l|l|l|}
\hline Indication & Outcome \\
\hline Frequency & Union & Nonunion & Total \\
\hline Primary surgery & $12(100 \%)$ & 0 & 12 \\
\hline Distal & 3 & 0 & 3 \\
\hline Waist & 6 & 0 & 6 \\
\hline Proximal pole & 3 & 0 & 3 \\
\hline Revision surgery & $7(77.8 \%)$ & $2(22.2 \%)$ & 9 \\
\hline Distal & 0 & 0 & 0 \\
\hline Waist & 6 & 1 & 7 \\
\hline Proximal Pole & 2 & 1 & 3 \\
\hline Total & $19(90.5 \%)$ & $2(9.5 \%)$ & 21 \\
\hline
\end{tabular}

delay from injury to surgery, primary versus revision surgery, use of bone graft, and surgical fixation demonstrated considerable heterogeneity $\left(\mathrm{I}^{2}>83 \%\right)$. Outcome variables of union rate by $\mathrm{CT}$, time to union, and complications were consistently reported among the studies ( - Table $\mathbf{1}$ ).

A total of 21 patients with an average age of 21.3 (range 15-29) years were treated with BMP for scaphoid nonunions in both primary and revision surgeries with a median followup of 24 months (range 2 months-6 years, - Table 1). Median amount of BMP used was 3.5 (range 0.53-50) $\mathrm{mg}$ with three different BMP types. Overall ANOVA of demographic variables demonstrated homogeneity among the studies, excluding the case report by Jones et $\mathrm{al}^{21}(p=0.43$, all pairwise $p>0.08$ ).

Overall union rate was $90.5 \%$ (19/21 patients, range 67$100 \%$ ) with a median CT-determined time to union of 2.5 (range 1.5-12) months. The rates of union with BMP in primary versus revision surgery were $100 \%(12 / 12)$ and $88 \%(7 / 9)$,

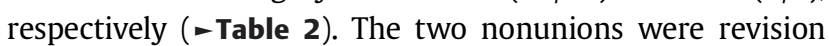
surgeries ( 1 waist, 1 proximal pole). ${ }^{24}$

Five out of twenty-one patients (23.8\%) had complications ( - Table 3). The total number of procedural complications was 11 for 29 surgeries (52.4\%) in 21 patients. The complication rates were persistent nonunions at $2 / 21(9.5 \%),{ }^{24} \mathrm{HO}$ at $4 / 21(19 \%),{ }^{24}$ reoperation at $3 / 21(14.3 \%),{ }^{24}$ and reduced range of motion at $1 / 29(4.8 \%)^{24}$

\section{Discussion}

Persistent scaphoid nonunions may result in carpal collapse and radiocarpal osteoarthritis, which can be debilitating and difficult to treat. ${ }^{29-31}$ The common treatment options prior to advanced wrist arthritis yield reasonable outcomes with a certain degree of morbidity. The purpose is to determine the benefit of BMP in surgical fixation of scaphoid nonunions. We found that BMP had a union rate of $90.5 \%$ without the use of vascularized bone graft; however, BMP efficacy is unclear, and the $\mathrm{HO}$ incidence warrants additional investigation with controlled trials to determine optimal BMP use and postoperative immobilization duration.
Table 3 Complications

\begin{tabular}{|c|c|c|}
\hline Patients & 21 & \multirow[t]{2}{*}{ Frequency (\%) } \\
\hline Surgeries & 21 & \\
\hline $\begin{array}{l}\text { Total patients with } \\
\text { complications }\end{array}$ & 5 & 23.8 \\
\hline $\begin{array}{l}\text { Total procedural } \\
\text { complications }\end{array}$ & 11 & 52.4 \\
\hline $\begin{array}{l}\text { Persistent } \\
\text { nonunion }\end{array}$ & 2 & $\begin{array}{l}9.5 \\
1 \text { Waist (revision) } \\
1 \text { Proximal pole (revision) } \\
\text { - Both underwent midcarpal } \\
\text { arthrodesis }\end{array}$ \\
\hline $\mathrm{HO}$ & 4 & $\begin{array}{l}19.0 \\
3 \text { Waist (revision) } \\
1 \text { Proximal pole (revision) }\end{array}$ \\
\hline Reoperation & 3 & $\begin{array}{l}14.3 \\
2 \text { Proximal pole (revision) } \\
\text {-HO excision with capsulectomy } \\
\text {-Midcarpal fusion } \\
1 \text { Waist (revision) } \\
\text { - Midcarpal fusion }\end{array}$ \\
\hline Decreased ROM & 1 & $\begin{array}{l}4.8 \\
1 \text { Proximal pole (revision) } \\
\text {-Associated with } \mathrm{HO} \text { and } \\
\text { reoperation }\end{array}$ \\
\hline Chronic pain & 0 & 0 \\
\hline Infection & 0 & 0 \\
\hline
\end{tabular}

Abbreviations: $\mathrm{HO}$, heterotopic ossification; ROM, range of motion.

\section{Limitations}

The primary limitations are the poor methodologic qualities of the included studies. All studies used BMP to augment bone graft, screw or wire fixation, or a combination of methods, confounding the interpreted efficacy of BMP in scaphoid nonunion surgery. Although we enumerate all complications reported, there is an inherent risk in retrospective studies of underreporting complications, which may have decreased pooled incidence. All complications were attributed to one study of revision cases, ${ }^{24}$ which may suggest publication and outcome reporting bias among the other studies. Further, there was considerable heterogeneity within the demographic and surgical variables, which was attributed to the variable fixation methods and use of bone grafting in the absence of standardized controls.

\section{Union Rate}

This review demonstrated a union rate of $90.5 \%$ (range $67-100,19 / 21$ patients). Pinder et al performed a metaanalysis in 2015 on union and complication rates based on graft type and fixation method (screws, K-wires, no fixation) from 48 publications involving 1,602 patients with scaphoid nonunions from 1999 to $2014 .{ }^{3}$ Overall union rate was $90 \%$ with CT and MRI in 18/48 studies (93\%, 95\% CI, 86-98). Union rate with nonvascular grafts was $88 \%$ (95\% CI 84-92), which was comparable to vascularized at $92 \%$ (95\% Cl, 85-96). Treatment with BMP was not included in their meta-analysis, and the results of the present study suggest a similar union rate. 
In this study, union with BMP and different types of bone grafts, or lack thereof, were reported for all 21 patients. The rates were $100 \%(5 / 5)$ for no graft with screws, $100 \%(9 / 9)$ for autologous ICBG with screws (3) and without fixation (6), 0\% $(0 / 1)$ for autologous distal radius with screw, and $86 \%(6 / 7)$ for allograft with screw (2, one persistent nonunion) and without (5). One theoretical use for BMP as an osteoinductive agent is to augment scaphoid nonunion surgery with allograft to limit donor site morbidity; however, there remain few reports in the literature of this use. ${ }^{3,32}$

\section{Complication Rate}

Our literature review demonstrated a patient complication rate of $23.8 \%$ (range $0-83,5 / 21$ patients with 11 total complications). All complications occurred in the revision setting and were comparatively higher than those observed in large reviews. Pinder et al found that complications other than persistent nonunion were inconsistently reported. ${ }^{3}$ The complication rates for fixation method was $7 \%$ for K-wires (434 patients, most common, HO, 3\%) and 5\% for screw fixation (645 patients, most common, hardware migration, $3 \%)$. Comparatively, HO was observed in four cases (19\%) and hardware migration was not observed; however, three patients (14\%) underwent a reoperation, including two midcarpal arthrodeses for persistent nonunion and $\mathrm{HO}$ excision with capsulectomy. A retrospective review of 1,670 cases of DRBG harvesting reported a $4 \%$ complication rate at 4.5 years. ${ }^{12}$ Bone graft failure requiring a reoperation of harvesting ICBG was the most common complication (2.3\%), followed by DeQuervain's tenosynovitis (1.3\%), local softtissue infection $(0.2 \%)$, and fracture through donor site (0.1\%). Pinder et al reported complication incidence at ICBG harvest site of $40 \%$ (most common, donor site pain/scar sensitivity/lateral femoral cutaneous nerve injury sequelae $42 \%$, iliac crest hyperostosis $28 \%$, hematoma $13 \%$, and infection $4.3 \%)^{3}$ Reoperation rates were rarely discussed, and the authors concluded with guidelines for consistent reporting to optimize future comparison.

In this analysis, all four cases with $\mathrm{HO}$ were observed in a single study and all four patients had scaphoid union. ${ }^{24}$ The one instance of a coincident complication was decreased wrist range of motion that required $\mathrm{HO}$ excision and capsulectomy. The authors attributed the high incidence of $\mathrm{HO}$ to the use of rhBMP-2, revision setting, and prolonged immobilization until determination of radiographic nonunion (3-5 months). The two cases of persistent nonunion in the study by Brannan et al later underwent scaphoid excision and midcarpal arthrodesis. ${ }^{24}$ The authors concluded that the risk of motion-limiting $\mathrm{HO}$ and reoperation limits the off-label use of rhBMP-2 in their practice to complex cases of scaphoid nonunion in young patients. ${ }^{24}$ There were no postsurgical infections reported in any of the studies. This is consistent with previous studies of BMP use in other locations. ${ }^{19}$

The largest study in this review was a randomized controlled trial and reported no complications in the 11 primary cases treated with BMP with either autologous or allogenic bone grafts. ${ }^{22}$ Bilic et al reported on a third group of six patients treated with autologous ICBG without BMP who all went on to scaphoid union at an average of 9 weeks. This time contrasted with the radiographic union at 4 weeks for the patients treated with autologous ICBG and BMP and 8 weeks for patients treated with allogenic ICBG and BMP, leading the authors to conclude that BMP accelerates time to union with autologous bone grafting and is a viable option for mitigating donor site morbidity with the use of allogenic bone grafting. However, the absence of an additional control group treated with BMP alone and without bone graft was not included and limits the interpreted efficacy of BMP when all patients in the study treated with either allograft or allogenic bone graft went on to union.

BMP use for scaphoid nonunion surgery is not currently FDA approved and must be performed with caution. While there may be a role for BMP use in scaphoid nonunion surgery, there is a paucity evidence to suggest that BMP alone promotes scaphoid union. A sufficiently powered, randomized controlled trial with sham BMP preparations is needed to determine the efficacy, dosing, and morbidity of the use of BMP.

\section{Note}

The views expressed in this article are those of the authors and do not reflect the official policy of the Department of Army, Defense Health Agency, Department of Defense, or the US Government.

\section{Ethical Approval}

All procedures followed were in accordance with the ethical standards of the responsible committee on human experimentation at the respective institutions of the cited articles and with the Helsinki Declaration of 1975, as revised in 2008 (5). Informed consent was obtained from all patients for being included in the cited studies. This article does not contain any studies with animal subjects.

\section{Funding}

None.

\section{Conflict of Interest}

None declared.

\section{References}

1 Hove LM. Epidemiology of scaphoid fractures in Bergen, Norway. Scand J Plast Reconstr Surg Hand Surg 1999;33(04):423-426

2 Merrell GA, Wolfe SW, Slade JF III. Treatment of scaphoid nonunions: quantitative meta-analysis of the literature. J Hand Surg Am 2002;27(04):685-691

3 Pinder RM, Brkljac M, Rix L, Muir L, Brewster M. Treatment of scaphoid nonunion: a systematic review of the existing evidence. J Hand Surg Am 2015;40(09):1797-1805.e3

4 Grewal R, Suh N, Macdermid JC. Use of computed tomography to predict union and time to union in acute scaphoid fractures treated nonoperatively. J Hand Surg Am 2013;38(05):872-877

5 Chang MA, Bishop AT, Moran SL, Shin AY. The outcomes and complications of 1,2-intercompartmental supraretinacular artery pedicled vascularized bone grafting of scaphoid nonunions. J Hand Surg Am 2006;31(03):387-396

6 Rancy SK, Swanstrom MM, DiCarlo EF, Sneag DB, Lee SK, Wolfe SW, Scaphoid Nonunion Consortium. Success of scaphoid nonunion 
surgery is independent of proximal pole vascularity. J Hand Surg Eur Vol 2018;43(01):32-40

7 Higgins JP, Burger HK. Proximal scaphoid arthroplasty using the medial femoral trochlea flap. J Wrist Surg 2013;2(03):228-233

8 Doi K, Oda T, Soo-Heong T, Nanda V. Free vascularized bone graft for nonunion of the scaphoid. J Hand Surg Am 2000;25(03): 507-519

9 Caporrino FA, Dos Santos JB, Penteado FT, de Moraes VY, Belloti JC, Faloppa F. Dorsal vascularized grafting for scaphoid nonunion: a comparison of two surgical techniques. J Orthop Trauma 2014;28 (03):e44-e48

10 Loeffler BJ, Kellam JF, Sims SH, Bosse MJ. Prospective observational study of donor-site morbidity following anterior iliac crest bonegrafting in orthopaedic trauma reconstruction patients. J Bone Joint Surg Am 2012;94(18):1649-1654

11 Kim DH, Rhim R, Li L, et al. Prospective study of iliac crest bone graft harvest site pain and morbidity. Spine J 2009;9(11):886-892

12 Patel JC, Watson K, Joseph E, Garcia J, Wollstein R. Long-term complications of distal radius bone grafts. J Hand Surg Am 2003; 28(05):784-788

13 Malizos KN, Dailiana Z, Varitimidis S, Koutalos A. Management of scaphoid nonunions with vascularized bone grafts from the distal radius: mid- to long-term follow-up. Eur J Orthop Surg Traumatol 2017;27(01):33-39

14 Tsantes AG, Papadopoulos DV, Gelalis ID, Vekris MD, Pakos EE, Korompilias AV. The efficacy of vascularized bone grafts in the treatment of scaphoid nonunions and Kienbock disease: a systematic review in 917 patients. J Hand Microsurg 2019;11(01): 6-13

15 Urist MR. Bone: formation by autoinduction. Science 1965;150 (3698):893-899

16 Even J, Eskander M, Kang J. Bone morphogenetic protein in spine surgery: current and future uses. J Am Acad Orthop Surg 2012;20 (09):547-552

17 Ong KL, Villarraga ML, Lau E, Carreon LY, Kurtz SM, Glassman SD. Off-label use of bone morphogenetic proteins in the United States using administrative data. Spine 2010;35(19):1794-1800

18 Swiontkowski MF, Aro HT, Donell S, et al. Recombinant human bone morphogenetic protein-2 in open tibial fractures. A subgroup analysis of data combined from two prospective randomized studies. J Bone Joint Surg Am 2006;88(06):1258-1265
19 Dai J, Li L, Jiang C, Wang C, Chen H, Chai Y. Bone morphogenetic protein for the healing of tibial fracture: a meta-analysis of randomized controlled trials. PLoS One 2015;10(10):e0141670

20 Kujala S, Raatikainen T, Ryhänen J, Kaarela O, Jalovaara P. Composite implant of native bovine bone morphogenetic protein (BMP) and biocoral in the treatment of scaphoid nonunions-a preliminary study. Scand J Surg 2002;91(02):186-190

21 Jones NF, Brown EE, Mostofi A, Vogelin E, Urist MR. Healing of a scaphoid nonunion using human bone morphogenetic protein. J Hand Surg Am 2005;30(03):528-533

22 Bilic R, Simic P, Jelic M, et al. Osteogenic protein-1 (BMP-7) accelerates healing of scaphoid non-union with proximal pole sclerosis. Int Orthop 2006;30(02):128-134

23 Ablove RH, Abrams SS. The use of BMP-2 and screw exchange in the treatment of scaphoid fracture non-union. Hand Surg 2015;20 (01):167-171

24 Brannan PS, Gaston RG, Loeffler BJ, Lewis DR. Complications with the use of BMP-2 in scaphoid nonunion surgery. J Hand Surg Am 2016;41(05):602-608

25 Rice I, Lubahn JD. Use of bone morphogenetic protein-2 (rh-BMP-2) in treatment of wrist and hand nonunion with comparison to historical control groups. J Surg Orthop Adv 2013;22(04):256-262

26 Liberati A, Altman DG, Tetzlaff J, et al. The PRISMA statement for reporting systematic reviews and meta-analyses of studies that evaluate healthcare interventions: explanation and elaboration. BMJ 2009;339:b2700

27 Higgins JP, Thompson SG. Quantifying heterogeneity in a metaanalysis. Stat Med 2002;21(11):1539-1558

28 Higgins JP, Thompson SG, Deeks JJ, Altman DG. Measuring inconsistency in meta-analyses. BMJ 2003;327(7414):557-560

29 Steinmann SP, Adams JE. Scaphoid fractures and nonunions: diagnosis and treatment. J Orthop Sci 2006;11(04):424-431

30 Waitayawinyu T, McCallister WV, Nemechek NM, Trumble TE. Scaphoid nonunion. J Am Acad Orthop Surg 2007;15(05):308-320

31 Werdin F, Jaminet P, Naegele B, Pfau M, Schaller HE. Reconstruction of scaphoid nonunion fractures of the proximal one third with a vascularized bone graft from the distal radius. Eplasty 2014;14:e24

32 Mahmoud M, Koptan W. Percutaneous screw fixation without bone grafting for established scaphoid nonunion with substantial bone loss. J Bone Joint Surg Br 2011;93(07):932-936 